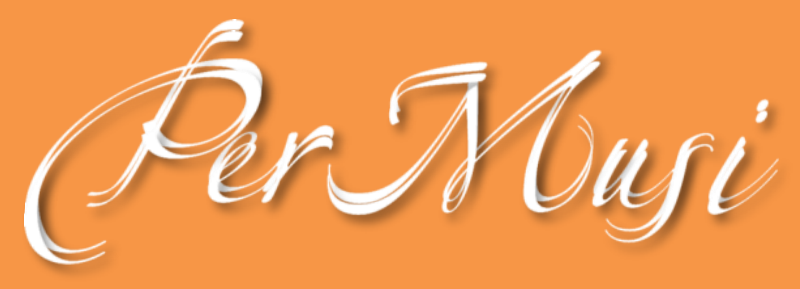

eISSN 2317-6377

\title{
Variações sobre um tema de Rimbaud
}

\author{
Célia Maria Domingues da Rocha Reis \\ https://orcid.org/0000-0003-0988-8803 \\ Universidade Federal de Mato Grosso, Letras \\ celiarochareis@gmail.com
}

José Augusto Duarte Lacerda

https://orcid.org/ 0000-0002-7714-2176

Universidade Federal de Mato Grosso, Música

zecalacperc@gmail.com
Aclyse de Mattos

https://orcid.org/0000-0003-1325-9233

Universidade Federal de Mato Grosso

Comunicação

aclyse@gmail.com

SCIENTIFIC ARTICLE

Submitted date: 17 may 2020

Final approval date: 06 nov 2020

Resumo: O artigo apresenta análise do poema "Cocheiro bêbado", de Rimbaud, tradução de Augusto de Campos. A versão em português potencializa, no plano da expressão, a impressão acústica dos deslocamentos dos personagens no enredo lírico. Mais especificamente, os ruídos, resultantes de figuras sonoras, acento simétrico, periodicidade etc., e alteram sensivelmente o modo de ler os versos. Em uma perspectiva, o poema sinaliza um processo de emancipação do ruído ocorrido tanto na poesia quanto na música, no final do século XIX, espraiando-se pelo XX, e que também culminou na ascensão do status dos sons percussivos. Procederemos a uma introdução teórica sobre os pontos referidos e, em seguida, buscando interação entre a versificação e a oralidade, entre o verso e a música, apresentaremos duas camadas de leitura, a sonoro-rítmica e a estrutural, cada qual com subdivisões específicas variações - suscitadas pelo poema. Para cada variação apresenta-se uma curta interpretação musical com percussão e respectiva partitura.

Palavras-chave: Literatura e música; Som, ruído e ritmo; Rimbaud.

\section{TITLE: VARIATIONS ON A THEME BY RIMBAUD}

Abstract: This article presents an analysis of the poem "Cocheiro Bêbado" by Rimbaud, translated by Augusto de Campos. The Portuguese version expressive ly high lights the acousticism pression of the characters' movements during the lyrical plot. More specifically, the noises - created from sound figures, symmetrical frequency, and periodicity - alter there adding of the verses. To an extent, "Cocheiro Bêbado" signals the emancipation of noise that occurs in both poetry and music at the end of the 19th century and during the 20th century, which also culminates in the ascension of percussive sounds. We Will proceed with a theoretical introduction on the points presented and follow - seeking an interaction between versification and orality, and between verse and music - by presenting two layers of reading, sound-rhythmic and structural, each with specific variation used by the poem. For each variation, we present a brief musical interpretation utilizing percussion instruments and their respective score.

Keywords: Literature and music; Sound, noise and rhythm; Rimbaud.

(ㄷ) (1) 


\section{Variações sobre um tema de Rimbaud}

Célia Maria Domingues da Rocha Reis, Universidade Federal de Mato Grosso, celiarochareis@gmail.com José Augusto Duarte Lacerda, Universidade Federal de Mato Grosso, zecalacperc@gmail.com Aclyse de Mattos, Universidade Federal de Mato Grosso, aclyse@gmail.com

\section{Introdução}

Jean Cohen $(1978,11)$ nos explica que, tradicionalmente, o verso é, em si, um "processo de poetização, só sendo possível existir como uma relação de som e sentido, uma estrutura fônica e semântica", "duplo poder" de realização. Do lat. versus, "retorno", indica o que volta sempre sobre si mesmo, por oposição a prorsus, prosa, que avança linearmente. O retorno e a repetição nucleiam os procedimentos de composição poética, mesmo em poemas sem padrões fixos, irregulares: marcações rítmicas (acentos), pausas, figuras de harmonia. Também a rima, cujo princípio o simbolista Verlaine, lembra Cohen $(1978,65)$, tributava como "a música antes de tudo". O som - os fonemas, o significante - são os elementos que se organizam mediante técnicas rítmicas que visam "criar efeitos acústicos por meio das palavras", a melopéia, diz Pound (1970). Tais recursos justificam o que Cohen $(1978,49)$ e outros teóricos defendem ardorosamente: "a poesia é feita para ser declamada". Defesa que, por um lado, retoma a prática milenar de transmissão oral da obra literária; por outro, aponta para as dificuldades de oralização dos poemas, que crescentemente desconsideram as relações fonossemânticas, pela separação de grupos sintaticamente solidários, de grupos verbais, nominais. Ainda, o labor criativo e inusitado com a própria matéria de construção dos versos, letras, fonemas, palavras.

De entre uma extensa tradição de poemas que laboram de maneira mais insistente com efeitos acústicos, ressalta-se o soneto "Cocher Ivre", do simbolista Rimbaud, na laboriosa tradução "Cocheiro bêbado", de Augusto de Campos $^{1}$, que intenta manter o fenômeno sonoro do poema original:

\section{Cocher Ivre}

Pouacre

Boit:

Nacre

Voit;

Acre

Loi,

Fiacre

Choit!

\footnotetext{
${ }^{1}$ O soneto em francês e a tradução em Campos, 1978, 254.
} 


\title{
Femme
}

Tombe:

Lombe

Saigne:

Geigne.

- Clame!

\section{Cocheiro bêbado}

Álacre
Vai:
Nacre
Rei;
Acre
Lei,
Fiacre
Cai!

Dama:

Tombo.

Lombo

Dói.

Clama:

Ai!

\begin{abstract}
A brevidade dos versos monossilábicos, nos quais se alternam encontros consonantais e ditongos, provocam o leitor a fazer uma leitura em ritmo acelerado e deslizante, donde resulta, para além dos sons das palavras pronunciadas, a impressão acústica de ruídos.
\end{abstract}

Os ruídos evocados entretecem uma paisagem sonora (ou "ruidosa") que vai além da musicalidade, fazendo convergir som e sentido, potencializando semanticamente o plano narrativo do poema (aspecto icônico do signo).

O estudo que ora apresentamos, num natural engendramento interdisciplinar, literatura e música, enfoca, então, essa dimensão sonora: não os sons definidos - o que é ouvido de imediato no verso, lido normalmente, mas os indefinidos, não dados culturalmente. Em uma oralização mais marcada em termos rítmicos, pode ficar audível outro espectro sonoro. Ou seja, a trama sonora aciona memórias de ruídos, incorpora ao poema ruídos que a ação visual descreve e acabam por criar uma ambiência diversa para a narrativa poética. Mais que simples métrica, os versos curtos guardam semelhança, por exemplo, com os passos repicados do cavalo que conduz o "fiacre". Temos então que a duração (elemento rítmico) também reforça, na sonoridade, a ambientação do poema.

Nesse sentido, verificamos que os versos propõem um jogo, desafio que aceitamos, fazendo nossas próprias apostas, com interpretação verbal e respectivas transcrições musicais, objetivando extrair-Ihes novas potências que, ao fim e ao cabo, coadunam-se na transmissão de uma condição dramática do ser humano. 


\section{Camadas de leitura}

O ruído apresenta, então, nessa análise, um caráter emancipado, e provoca o poema a transcender o silêncio da página, estimulando o leitor a acionar outros sentidos e percepções da realidade e do conjunto cultural que ela oferece, em diálogo ativo com a tradição. Isso evita a ossificação de soluções artísticas mais contemporâneas em nome de modos convencionais de leitura, valorizando os poetas.

Em 1913, o artista plástico e músico futurista italiano Luigi Russolo, explicou e defendeu a utilização do ruído nas expressões performáticas dos futuristas, na música, em carta que constituiu marco na história da música moderna, posteriormente publicada na forma de manifesto com o título L'Arte dei Rumori (2004).

Russolo afirmou que os sons considerados musicais (as notas musicais Lá, Si, Dó etc.) e sua pretensa "sensibilidade" haviam sido exauridos. A Revolução Industrial e o decorrente advento dos ruídos havia deslocado a atenção e o interesse de artistas para estes sons $(2004,4)$. O heterônimo de Fernando Pessoa (1998, 306), Álvaro de Campos (1890-1935), engenheiro, dado às modernidades e às sensações, endossa² a assertiva do artista italiano em "Ode triunfal", da qual apresentamos o excerto:

Ó rodas, ó engrenagens, $r-r-r-r-r-r$-r eterno!

Forte espasmo retido dos maquinismos em fúria!

Em fúria fora e dentro de mim,

Por todos os meus nervos dissecados fora,

Por todas as papilas fora de tudo com que eu sinto!

Tenho os lábios secos, ó grandes ruídos modernos,

De vos ouvir demasiadamente de perto,

E arde-me a cabeça de vos querer cantar com um excesso

De expressão de todas as minhas sensações,

Com um excesso contemporâneo de vós, ó máquinas!

Em sua carta, Russolo esclarece que, dos primórdios ("povos primitivos") à Renascença, era atribuída uma origem divina aos sons musicais. O som era então algo à parte da vida cotidiana $(2004,5)$. Nessa condição (que chegou ao ápice com o Romantismo), os sons considerados musicais eram demasiadamente restritos à "variedade e qualidade dos timbres", ficando as orquestras limitadas a poucas famílias instrumentais ${ }^{3}$. As sensações que os compositores românticos procuravam passar com a utilização dos sons musicais tradicionais ${ }^{4}$ levavam o ouvinte do século XX ao "tédio". Ao contrário, Russolo afirmava: "Nós temos um prazer infinitamente maior imaginando combinações dos sons dos bondes, dos automóveis e de outros veículos, das multidões barulhentas, do que ao ouvir mais uma vez, por exemplo, as sinfonias heroicas ou pastorais" 5 (2004, 7). Fazendo uso de categorizações, Russolo propõe novas famílias de sons, todos ruídos, que deveriam ser explorados pela música futurista (ou a música a partir de então), aqui por nós sintetizados em: 1. Rugidos (roars, claps, noises fallingwater, driving noises, bellows); 2. Sibilos e roncos (whistling,

2É possível considerar a concomitância das datas - a de 1913, do lançamento do manifesto, e o contexto em que Fernando Pessoa visualizou o seu heterônimo, construindo a biografia ficcional dele.

${ }^{3}$ Instrumentos de cordas friccionadas, de cordas pinçadas, instrumentos de sopro metálicos, instrumentos de sopro de madeira e instrumentos de percussão (Russolo, 2004).

${ }^{4}$ Sons produzidos pelos instrumentos musicais que compõem os grupos sinfônicos e camerísticos através da execução de maneira tradicional, i.e., arco friccionando a corda produzindo altura definida para instrumentos como o violino etc.

${ }^{5}$ Clara referência às sinfonias 3 e 6 de Beethoven. 
snores, snorts); 3. Sussurros e grunhidos (whispers, mutterings, rustlings, grumbles, grunts, gurgles); 4. Guinchos e sons raspados (screeching, creaking, rustling, buzzing, crackling, scraping); 5. Sons obtidos através da percussão em metais, madeiras, peles, pedras, cerâmica etc.; 6. Vozes de animais e pessoas (Voices of animal sand people, Shouts, Screams, Shrieks, Wails, Hoots, Howls, Death rattles, Sobs) (Russolo, 2004, 10).

Ruídos, como os listados pelo artista italiano, são os sons originados por ondas sonoras aperiódicas e, portanto, complexas. Por sua complexidade acústica, tais ondas não produzem alturas ("notas") definidas. São, portanto, na linguagem teórica musical, sons de alturas indefinidas, como, por exemplo, a altura Lá, produzida por um diapasão. A nota Lá é a resultante de ondas sonoras que se repetem com uma frequência periódica em torno de $442 \mathrm{~Hz}$, ou seja, 442 batidas por segundo. Dentre as famílias de sons propostas por Russolo, podemos destacar os instrumentos de percussão, que são fonte inexaurível de ruídos.

Os anseios de compositores do século XX - como o próprio Russolo (e.g. Risveglio di una Città, de 1913) e Henry Cowell (e.g. The Banshee, de 1925), Edgard Varèse (e.g. Ionisation, de 1931), John Cage (especialmente a partir de 1938, com obras como Imaginary Landscape No. 1) e Pierre Schaeffer (e.g. Étude Aux Chemins de fer, de 1948) - em expandirem a sua paleta sonora para além de sonoridades consideradas belas e tonais, em direção a sonoridades que refletissem a cacofonia urbana, levou-os a uma crescente busca pela exploração dos ruídos. Em decorrência dessa crescente busca por sonoridades comuns à realidade, mas incomuns na música até então, Cage influenciou largamente gerações futuras, sendo um dos pioneiros na utilização de objetos achados, como rádios, pedras, plantas e galhos, tambores de freios de automóveis etc. Essa busca, naturalmente, também estimulou o aumento do uso de instrumentos de percussão. Pode-se afirmar, portanto, que o processo de emancipação do ruído levou a uma ascensão do status da percussão, de mera acompanhadora a elemento tematicamente essencial na música contemporânea.

O manifesto de Russolo vem ao encontro do nosso propósito de lidar com a camada sonora do poema de Rimbaud, não só pela condição imitativa da realidade, mas também pela expressividade dos sons, pela percepção de que "na prolação dos fonemas, [há] um certo poder de sugestão semântica" (Monteiro, 1991, 85), pela construção rítmica, pela condensação (Pound 1970) de aspectos que, não obstante, apresentam dilatado conteúdo.

No âmbito da compreensão semantizada das propriedades sonoras, há ainda a questão da dicção dos versos - fôlego, intensidade, andamento. Alfredo Bosi, tratando da dinâmica do ritmo, explica que, em relação à maior ou menor força empregada na emissão das sílabas (tônica/átona), essa força incide em temporalidade, sendo o fôlego durativo, posto que a ele se subordinam "intensidade e aceleração do discurso". Essa força é de natureza anatômica e social:

Na prática verbal, a força e o tempo servem a momentos de expressão em contextos significativos. Dizer com mais veemência uma determinada frase, ou certa parte desta, é exercer sobre a matéria sonora uma dose de energia que intenciona essa mesma matéria. As exigências da situação em que age ou sofre o sujeito regem também o andamento da elocução. O fenômeno inteiro é, desse modo, articulatório e social. [...] na composição poética, o uso da alternância faz supor a aplicação inconsciente de um princípio ciclóide, "orgânico", da energia vocal. O ritmo, enquanto periodicidade, teria este sentido: ser presença sonora da Força, ser Vontade, ser o desejo no seu eterno retorno. O ritmo não se 
limita a acompanhar simplesmente o poema: arrasta-o para os esquemas do corpo." (Bosi 2010, 80-1, 112)

É interessante ressaltar que a ideia, no instante em que é expressa por meio da frase, ativa efeitos rítmicos da língua que,

[...] em virtude do novo contexto, se torna significativo. É a análise do estilo que desvenda as correlações possíveis entre ritmo e sentido. [...]. Um mesmo pensamento pode ser explorado por frases diversas em ritmos diversos conforme os matizes da percepção a serem configurados. [...]. O tremendo poder de síntese da frase poética envolve a imagem, o conceito e o som que sai do corpo humano [...]." (Bosi 2010, 105-106)

Pelas citadas razões acústicas, históricas e estilísticas, e tendo como procedimento essa pesquisa dos sons, foi possível fazer diferentes interpretações, que denominamos "camadas de leitura", e estabelecer variações rítmicas com os versos de Rimbaud. Optamos pela utilização de instrumentos de percussão de forma a "musicar" - proceder à transcrição musical - as nossas diferentes interpretações de o "Cocheiro Bêbado"6. Esse constructo mostra, para além da aproximação, a relação crucial que há entre música e poesia.

Para a confecção das transcrições musicais, optamos pela utilização de timbres que evocam as sonoridades a serem descritas nas interpretações. Utilizamos instrumentos percussivos de, basicamente, duas categorias, membranofones e idiofones. Os membranofones são instrumentos cuja sonoridade é produzida através da percussão sobre uma membrana ("pele") afixada sobre um corpo, em geral cilíndrico, e a decorrente vibração produzida por meio desta ação. Os idiofones são instrumentos em que a percussão sobre o próprio corpo do instrumento, e sua decorrente vibração, é responsável pela produção sonora (Cook 1997, 2-3). Dentre os membranofones, optamos pela utilização de duas congas (ou tumbadoras - tambores afrocubanos típicos) e um tímpano (tambor que emite notas musicais definidas ${ }^{7}$ ). Dentre os idiofones, utilizamos um raspador, especificamente um reco-reco feito de bambu, e dois objetos de metais ressonantes encontrados, em sintonia com a ideia (John) cageana de utilização de found objects, para além dos instrumentos tradicionais ${ }^{8}$. Conforme a bula apresentada na Figura 1, para a transcrição utilizamos a grafia musical ocidental tradicional, com uso de pauta e durações. O tipo de notação musical que escolhemos assemelha-se ao que Cook chama de "conventional staff notation" (1997, 84). Em seu exemplo, Cook contempla o uso de abreviações indicativas sobre a pauta, pois a quantidade de instrumentos utilizados exige que certas linhas ou espaços da pauta sejam reservados a mais de um instrumento. No nosso caso, o número limitado de instrumentos torna as abreviações desnecessárias:

\footnotetext{
${ }^{6}$ Salientamos que a história da música a partir do século XX está repleta de obras que combinaram a voz, por intermédio de textos, poéticos ou não, com a percussão. A exemplo, citamos: Stuart Saunders Smith (e.g Poems I, II, III, 1970), Vinko Globokar (e.g. Toucher, 1973)), Georges Apherghis (e.g. Le Corps à corps, 1978), Frederic Rzewski (e.g. De Profundis, 1992) e Thomas DeLio (...sound/shivering/silence, 2013).

7 Têm origem no Oriente Médio, mas com recorrente utilização e desenvolvimento na música de concerto Ocidental desde a Renascença.

${ }^{8}$ Para referência: https://www.youtube.com/watch?v=SSulycqZH-U
} 


\section{Bula}

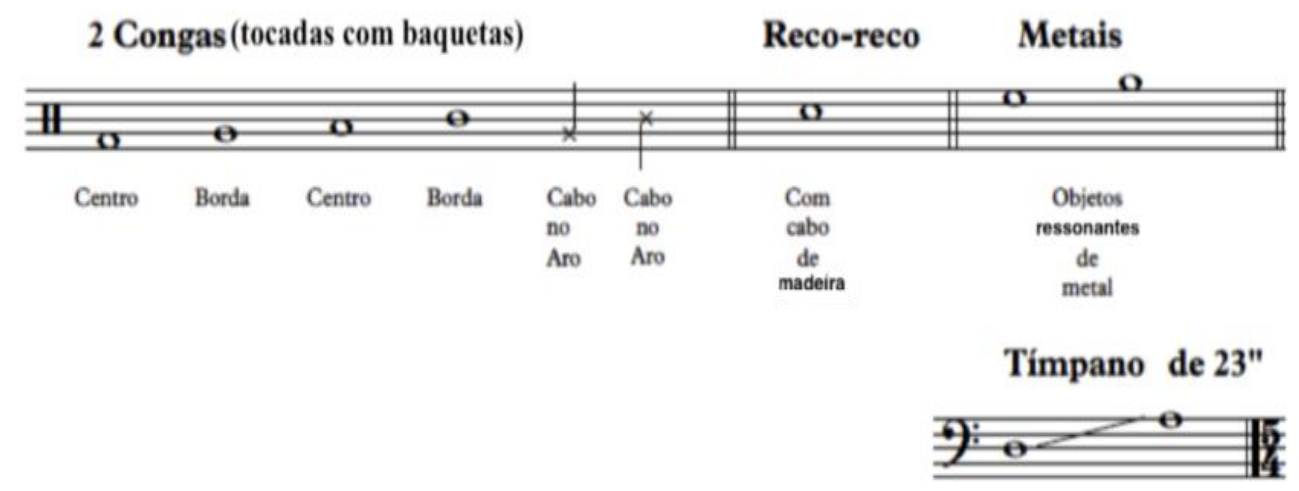

Figura 1: Bula demonstrando os instrumentos de percussão no pentagrama musical

\subsection{Camada de Leitura 1: Sonoro-rítmica}

\section{I) Variação 1.1. A configuração do soneto}

Nessa variação, propomos um foco no modo de construção do poema: a sua forma lírica. A leitura será feita respeitando a organização estrófica em soneto. Os versos são bem pontuados, o que propicia um direcionamento na leitura da pausa (o silêncio do verso), da métrica, da quebra do verso para o seguinte, na organização estrófica, segundo a opção do poeta.

Será considerado o acento das paroxítonas, preponderantes, que, nos quartetos, apresentam forte apelo aos sensores. No primeiro quarteto, apelo visual: o personagem cocheiro, com uma luminosidade "nacre" ("nácar", madrepérola), que conflui e é intensificada pela sua descrição interna, "álacre" (alegre, vivo, animado), conduz um "fiacre", antiga carruagem de aluguel, em geral puxada por um só cavalo; no segundo, apelo gustativo e olfativo - "acre" (amargo ao paladar; ou, odor forte ao olfato; em sentido figurado, rude). No primeiro terceto, visual: a queda da dama; no segundo, auditivo, com a interjeição em discurso direto.

\section{Cocheiro bêbado}

Álacre

Vai:

Nacre

Rei;

Acre

Lei,

Fiacre

Cai!

Dama:

Tombo.

Lombo

Dói.

Clama: 
Na Figura 2, abaixo, apresentamos a partitura, resultante de nossa interpretação sonora desta variação que, em termos musicais, constitui o tema. As durações seguem o ritmo da gravação de uma oralização feita por um de nós. As vogais abertas são interpretadas nas bordas das congas, por conta de seu timbre mais agudo (em relação ao centro do instrumento). Para a sonoridade mais abrasiva do monossílabo "rei", optou-se pela utilização do cabo da baqueta na borda da conga aguda. As notas indicativas de reco-reco estão sobre os encontros consonantais que evocam tal sonoridade. As exclamações agudas e ressonantes foram transcritas para os objetos de metal. Por opção estilística utilizamos o tímpano, respeitando a melódica descendente feita pela voz, para a abertura da terceira estrofe.

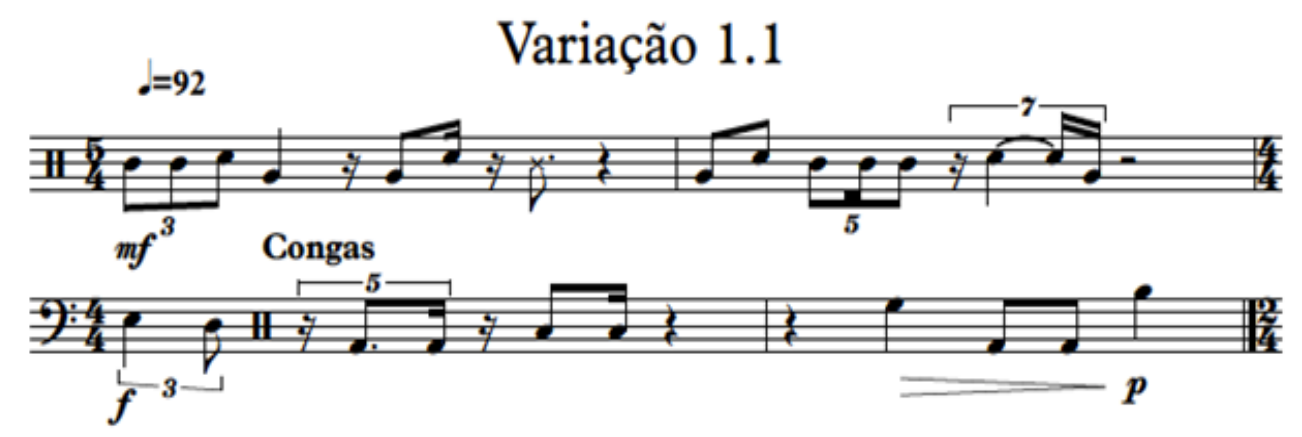

Figura 2: Variação 1.1

\section{II) Variação 1.2: relações fonossemânticas}

Aqui, faremos uma leitura sintática, que respeita às relações fonossemânticas, o encadeamento, desconsiderando a quebra dos versos, experimentando o caráter de narratividade que o texto apresenta:

Cocheiro bêbado

$$
\begin{aligned}
& \text { Álacre/Vai: } \\
& \text { Nacre/Rei; } \\
& \text { Acre/Lei, } \\
& \text { Fiacre/Cai! } \\
& \text { Dama:/Tombo. } \\
& \text { Lombo/Dói. }
\end{aligned}
$$

Clama:/Ai!

A partitura resultante de nossa interpretação sonora desta variação - Figura 3, apresenta métrica binária. A utilização de rítmica mais regular em comparação ao tema e a velocidade mais rápida (164 batidas por minuto) evocam o encadeamento proposto:

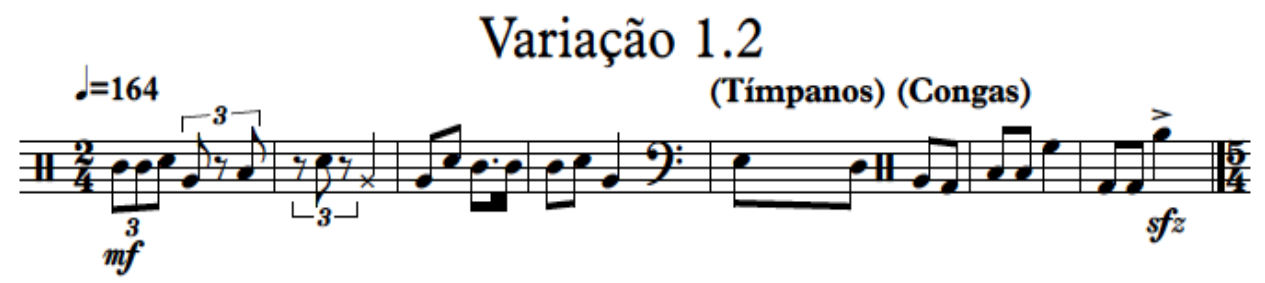

Figura 3: Variação 1.2 


\section{III) Variação 1.3: expressividade dos sons}

Priorizamos, nesta variação, as imagens sonoras, com ênfase na expressividade (simbolismo) dos sons ${ }^{9}-$ os encontros consonantais em cr; ditongos ei ai oi; nasais om am.

Segundo Martins (1991,54), consoantes oclusivas surdas como k, "pelo seu traço explosivo, momentâneo", reproduzem "ruídos duros, secos, de batidas, [...]; combinada à vibrante alveolar $r$, que também sugere atrito, em aliteração, resultam no efeito interpretável dos sons dos cascos do cavalo que conduz o fiacre, o seu trotar.

Em relação aos sons orais, Martins $(1991,50)$ informa que a vogal "a" pode sugerir ideias de "amplidão, alegria", sentimento predominante no primeiro quarteto. No entanto, há oscilação sonora no conjunto das estrofes. A sequência de ditongos é composta com as vogais e a o, respectivamente, anterior, central e posterior, e com a vogal medial anterior $\mathrm{i}$, som agudo, estridente, produzido pelo estreitamento do conduto bucal, que pode indicar "ser de ordem moral" (Martins, 1991, p.50). Considerando essa hipótese, há uma relação fonética motivada na construção dos versos. Em gradação, expõem o brilho e a decadência do personagem cocheiro. Assim, fazendo um rearranjo do jogo acústico criado nos versos:

\section{Cocheiro bêbado}

Álacre
Nacre
Acre
Fiacre
Rei
Lei
Vai
Cai
Dói
Ai!
Tombo.
Lombo
Dama:
Clama:

Por outro lado, os tercetos são nasalizados, de efeito de entoação mais prolongada (Martins 1991, 53). Criase uma onomatopeia com a combinação da oclusiva " $\mathrm{t}$ " com a nasal "om", em "tombo", causando a impressão acústica de batida.

É interessante observar que, na tradução, Campos optou por recriar de maneira diferenciada a ocorrência trágica da queda, retirando a imagem do sangramento, e a indicação da reação da dama, o seu clamor, o grito. Nos versos em francês, o narrador mantém a voz, em discurso direto enfático:

\footnotetext{
${ }^{9}$ Para indicar tais efeitos, os linguistas fazem levantamento estatístico em determinado conjunto de poemas, verificando sons recorrentes e suas possibilidades semânticas.
} 
Saigne:

Geigne.

- Clame!

São verbos colocados em modos verbais diferentes, imperativo, subjuntivo, imperativo. Talvez a opção tenha sido a de manter a rima, pois a flexão do verbo geindre no imperativo é geins. Fazendo uso do imperativo no verso derradeiro, ele instiga a dama à expressão de sua indignação ("clame" é traduzido também como declare), postura mais politizada, de reivindicação.

Ao invés desse recurso, Campos impõe uma subjetividade, pela indicação do sofrimento físico e pelo grito instantâneo, audível, também em discurso direto:

Dói.

Clama:

Ai!

Considerando o seu pendor concretista em cultivar uma arte que não "apresente", mas que "presentifique" o objeto (Campos; Pignatari; Campos 2006,46), pensamos que houve uma ideia de inserção do ditongo para intensificar o jogo sonoro.

É interessante ressaltar que, embora tenhamos encontrado correspondências de sons, a ambiência do poema se constrói, lembra-nos Alfredo Bosi $(2010,66)$, "em todo o processo de sonorização do tema, que enlaça o jogo de ecos e contrastes, o ritmo, o metro, o andamento da frase e a entoação".

A Figura 4, partitura da transcrição musical desta variação, mostra um foco na compartimentalização dos timbres. Cada compasso, unidade musical que denota métrica, contém a transcrição de uma estrofe. No primeiro compasso, há o predomínio do reco-reco, que realça os encontros vocálicos. No segundo compasso, foca-se na rítmica de uma nota por pulso, realçando os monossílabos. Este compasso também apresenta um crescendo - termo musical de gradativo aumento de intensidade sonora - para construção de tensão. No último compasso há o uso exclusivo dos tambores, com alternâncias entre tons abertos, denotando as sílabas tônicas, e sons destacados (com o sinal musical de stacatto sob as notas), marcando as sílabas que fecham as paroxítonas.

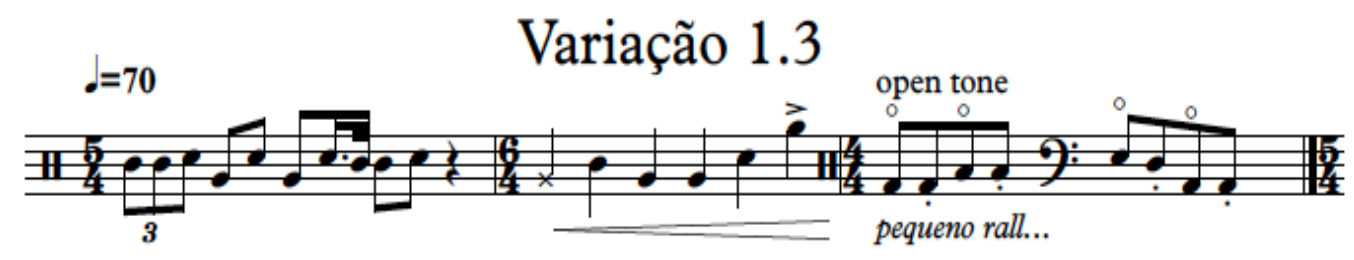

Figura 4: Variação 1.3

\subsection{Camada de Leitura 2: Estrutura de enredo e personagens}

\section{I) Variação 2.1: o enredo}

O título do poema é bastante expressivo e oferece ao leitor um código para interpretação de amplos aspectos do poema, constituindo-se, pode-se dizer, como um primeiro verso, um monóstico, pela carga informativa que condensa. Apresenta-se o protagonista, o "cocheiro", qualificado - "bêbado", situação inicial já conflituosa, de perigo iminente, pela sua função de conduzir o cavalo que puxa o fiacre. 
Há um eu lírico, ou um narrador onisciente, que o descreve no deslocamento: "Álacre vai", visualizando a sua figura de condutor alegre e rubro pelo efeito da bebida e, entrando na mente do personagem, mostrao como se sente em seu estado ébrio: "rei". É possível também compreender que apresenta a imagem de um rei em um trono, um rei caricato.

No segundo quarteto dá-se o clímax: a condução vacilante do alegre cocheiro/rei descamba e o fiacre cai: "acre lei". A realidade natural se impõe através da ação narrativa descrita, no caso, a lei da gravidade que faz tombar o fiacre ${ }^{10}$. Temos, então, nos dois quartetos, a descrição da cena externa: o cocheiro e seu fiacre se acidentam pela condução desastrosa.

Contudo, ao passarmos aos tercetos, que apresentam o desfecho, ocorre inversão: há uma "dama"/passageira assumindo o protagonismo como vítima da ação do cocheiro/rei caricato, e este desaparece do enredo; a descrição da cena narrada passa a ser interna ao fiacre - descreve-se o tombo da dama dentro da carruagem. Assim ordenando este breve soneto, Rimbaud antecipa efeitos das narrativas modernas ao alternar as figuras que protagonizam a trama.

Atuando com os verbos de ação propriamente, coloca-se em evidência nos versos a situação inicial conflito/clímax - desfecho.

\section{Cocheiro bêbado}

Vai:

Cai!

Dói.

Clama:

Ai!

A transcrição musical desta variação se encontra na Figura 5, e está centrada nos timbres e durações rítmicas que denotam as sonoridades produzidas pela voz durante a leitura. No primeiro compasso utiliza-se o tímpano por conta da possibilidade de se mudar gradativamente a nota, de agudo para mais grave, seguindo a melodia dada pela voz na nossa gravação, e ilustrando o verbo que virá a seguir ("cai"). O segundo e o último compasso põem em foco a utilização dos metais denotando as exclamações. O terceiro compasso apresenta um rulo (rápida sucessão de notas) tocado com cabo de baqueta no aro da tumbadora, ilustrando a rouquidão da voz que sente dor.

\footnotetext{
${ }^{10}$ Os versos ainda não estão sob os efeitos da Lei Seca, que proíbe condutores alcoolizados. Mas em escolas de ensino médio onde apresentamos o poema, muitos jovens estudantes fizeram conexão entre a narrativa do soneto e a Lei Seca.
} 


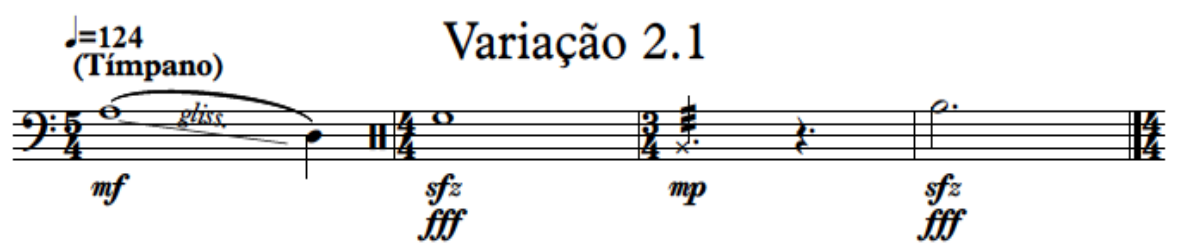

Figura 5: Variação 2.1

\section{II) Variação 2.2: os personagens}

Visualizamos as ações, em versos distintos, pelo protagonismo das personagens. Da mesma forma, é possível articular uma variação de leitura das personagens.

Numa interpretação mais dilatada, as personagens do cocheiro trabalhador e da dama nobre estão, ambos, no mesmo "fiacre" da história, sujeitos às reviravoltas cada vez mais velozes da modernidade que começa a se insinuar no ritmo das cidades. O poeta, sensível ao seu tempo, constrói com esses elementos seu soneto, tomando para sua poética não a lírica tradicional, mas o drama, a sátira, ou uma comédia de situação. Haveria alguma crítica de Rimbaud à sociedade francesa que, mesmo décadas após a Revolução que destituiu a nobreza, ainda acalentava uma nostalgia da aristocracia imperial? (Napoleão III etc.). E seria todo o soneto uma analogia com a queda de um velho modo de ver e reger o mundo?

\section{Cocheiro bêbado}

Rei;

Cai!

Dama:

Clama:

Ai!

A Figura 6 apresenta a transcrição musical desta variação. As escolhas de timbres condizem com as variações anteriores, com o diferencial da utilização do tímpano no terceiro e quarto compassos. Esta escolha se deu pelo fato de o instrumento poder mimetizar a melodia, primeiramente ascendente, depois, descendente da voz, como visto nesses compassos.

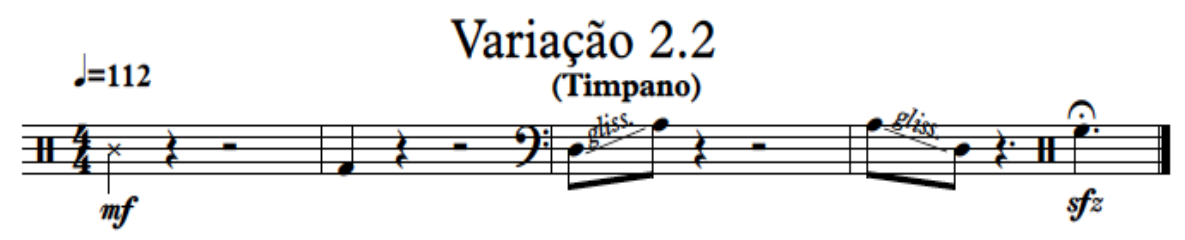

Figura 6: Variação 2.2

\section{Considerações finais}

Hugo Friedrich afirma que Rimbaud, em toda a sua obra,

[...] fala de música. Ele a chama "a música desconhecida", escuta-a em "castelos construídos com ossos", na "canção metálica dos postes do telégrafo"; "é canto límpido da nova desgraça", é "a música mais intensa", na qual foi suprimido todo o "sofrimento 
harmonioso" de tipo romântico. Quando sua poesia deixa ressoar coisas ou seres, há sempre gritos e bramidos que se interpolam na canção e no canto: música dissonante." $(1991,63)$

O horizonte da poesia e da música se predispunha ao novo, ao desconhecido, numa cidade tornada laboratório de expressões artísticas dos novos e intensos paradoxos captados pelos sentidos.

Os elementos sonoros - altura, timbre, duração - potencializam a palavra, ampliando-lhe a natureza simbólica. Por sua vez, o arranjo poético dos sons evoca simbolismos. A palavra, no contexto de um poema, ultrapassa a dimensão meramente pragmática, usual. Há uma dimensão na palavra poética que não pode ser reduzida ao seu uso ou conceito. Ela não é apenas uma ideia, mas uma maneira de evocação sensível. Rimbaud explora tal senda, lembrando-nos que os ruídos, os sons dissonantes, a violência da queda (do fiacre) e do sangue (da dama) também são quadros de afetação da sensibilidade. A poesia começa a dar autonomia ao ruído. $O$ crescimento das cidades coloca o ruído como um figurante principal nas ruas movimentadas. A música incorpora os ruídos com seu potencial expressivo.

Desenvolver essas variações a partir do pequeno soneto de Rimbaud nos possibilitou vislumbrar um momento criativo em que as formas musicais e líricas estavam em convulsão. A confluência de saberes literários, musicais e comunicativos que empreendemos permitiu a contemplação da obra por diversas angulações. Se a arte do cinema nos permite observar uma mesma cena tomada de vários ângulos e, com isso, aumentar a nossa capacidade de percepção de um mesmo fato, essas variações colhidas interdisciplinarmente trazem um pequeno lampejo das inumeráveis possibilidades de sentido que os versos irradiam a partir do ruído de cada palavra. Álacres vamos, no dorso do poema.

\section{Referências}

Andrade, Oswald. 1975. Poesias reunidas. Obras Completas. Rio de Janeiro: Civilização Brasileira.

Bosi, Alfredo. 2000. O ser e o tempo da poesia. São Paulo: Companhia das Letras.

Campos, Augusto de, Pignatari, Décio, e Haroldo de Campos. 2006. Teoria da poesia concreta: textos críticos e manifestos. Cotia-SP: Ateliê.

Campos, Augusto de. 1978. Verso, reverso, controverso. São Paulo: Perspectiva.

Cohen, Jean. 1978. Estrutura da linguagem poética. São Paulo: Cultrix.

Cook, G. 1997. Teaching Percussion. New York: Schirmer Books.

Friedrich, Hugo. 1991. Estrutura da lírica moderna. São Paulo: Duas Cidades.

Pessoa, Fernando. 1998. Obra poética. Rio de Janeiro: Nova Aguilar.

Pound, Ezra. 1970. ABC da Literatura. São Paulo: Cultrix.

Ramos, Maria Luiza. 1972. Fenomenologia da Obra Literária. 2ed. Forense: Rio de Janeiro.

Russolo, Luigi. 2004. The Art of Noise (futurist manifesto, 1913). Trad. para o inglês por Robert Filliou. Great Bear Pamphlet. Disponível em: ubuclassiscs.com Acesso em: Março, 13, 2018. 